\title{
Sindrom Komisura Wernekink; Patofisiologi dan Diagnosa: Sebuah Tinjauan Literatur
}

\author{
Novi Jayanti Sukarno Putri \\ Fakultas Kedokteran Universitas Lampung
}

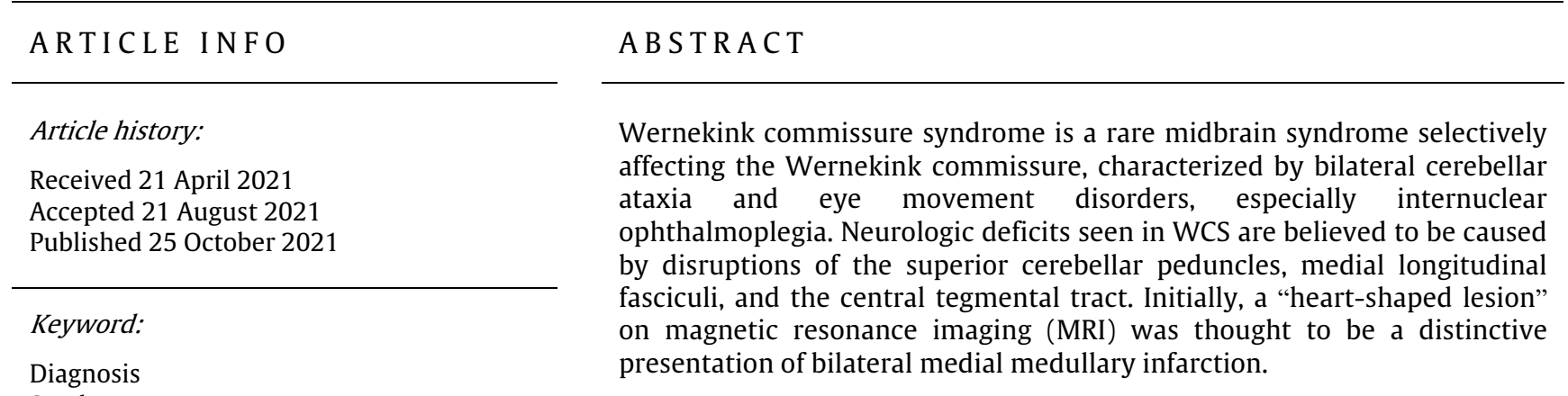

Syndrome

Pathophysiology

Magnetic resonance imaging

Wernekink commisure

This open access article is under the CC-BY-SA license.

\begin{abstract}
Kata kunci:
Diagnosa

Sindrom

Patofisiologi

Magnetic resonance imaging

Wernekink Komisura

*) corresponding author

Fakultas Kedokteran Universitas Lampung Jl. Prof. Dr. Ir. Sumantri Brojonegoro No. 1

Gedong Meneng, Kec. Rajabasa

Kota Bandarlampung, Indonesia,

A B S T R A K

Sindroma commissure Wernekink adalah sindrom midbrain yang langka yang secara selektif mempengaruhi komisura Wernekink, ditandai dengan ataksia serebelar bilateral dan gangguan pergerakan mata, terutama oftalmoplegia internuklear. Defisit neurologis yang terlihat pada WCS diyakini disebabkan oleh gangguan pada tangkai serebelar superior, fasciculi longitudinal medial, dan traktus tegmental sentral. Pemeriksaan radiologis yang berguna yaitu pada magnetic resonance imaging (MRI) dimana didapatkan gambaran "Lesi berbentuk hati" yang dianggap sebagai gambaran khas dari infark medular medial bilateral.
\end{abstract}

Telp. 082176010169

Email: novijayanti911@gmail.com

DOI: $10.47679 /$ makein.202133

This open access article is under the CC-BY-SA license.

\section{PENDAHULUAN}

Sindroma commissure Wernekink adalah sindroma midbrain yang langka, yang secara selektif mendestruksi komisura Wernekink yang melibatkan dekusasio serebelar superior di midbrain. Dengan prevalensi antara 0,7 dan 2,3\% akibat suplai kompleks ke midbrain, infark midbrain murni sangat jarang terjadi (Alhayek, Aldabbour, I, \& Alanbar, 2020; Savoia, Hashemiaghdam, Schindler, \& Salardini, 2020). Sindrom midbrain akibat serangan vaskular, seperti sindrom Weber, Benedict dan Claude, biasanya memengaruhi midbrain atas dan menghasilkan gambaran klinis yang didominasi oleh kelumpuhan saraf okulomotor dengan hemiparesis kontralateral, hemiparesis dengan gerakan tak sadar, dan ataksia. Lesi midbrain bawah jauh lebih jarang dan gejalanya kurang dikenali. Sindroma commissure Wernekink adalah sindrom yang sangat langka karena lesi tunggal yang ditempatkan secara strategis di midbrain caudal paramedian yang melibatkan seluruh dekusasi tangkai serebelar superior, menghasilkan gejala bilateral (Alhayek et al., 2020).

Sindroma ini diikuti stroke paramedian di caudal midbrain di tingkat colliculus inferior. Degenerasi olivari hipertrofik (HOD), dengan atau tanpa tremor palatal, terjadi 
beberapa bulan setelah stroke awal karena terputusnya inferior olives dari nukleus mesencephalic red dan nukleus dentate serebelar (Liu, Qiao, \& He, 2012). Defisit neurologis yang terlihat pada WCS diyakini disebabkan oleh gangguan pada pedunkel serebelar superior, fasciculi longitudinal medial, dan traktus tegmental sentral. Hal ini ditandai dengan sindrom serebelar bilateral, kadang-kadang berhubungan dengan gangguan pergerakan mata dan tremor palatal. Sindroma commissure Wernekink pertama kali dijelaskan oleh Lhermitte pada tahun 1958 (Savoia et al., 2020).

\section{METODE}

Suatu tinjauan literatur (literatur rewiew) terhadap teori-teori yang relevan. Sumber tinjauan meliputi studi pencarian sistematis database (proquest, ebsco, elsevier, google cendikia) yang berjumlah 10 jurnal.

\section{HASIL DAN DISKUSI}

Midbrain disuplai oleh cabang-cabang arteri serebral posterior, komunikans posterior, koroidal anterior, dan arteri serebelar superior. Cabang paramedian dari arteri serebral posterior dan arteri komunikan posterior memasok struktur midline termasuk nukleus okulomotorik, fasikuli longitudinal medial, dan bagian medial dari substansia nigra. Cabang paramedian dianggap sebagai arteri yang terlibat dalam sindroma commissure Wernekink (Liu et al., 2012).

Area paramedian midbrain dan talamus disuplai melalui cabang perforasi interpeduncular fossa, terutama timbul dari ujung arteri basilar, arteri serebelar superior, serta dari segmen pra-komunikasi dari arteri serebral posterior. Cabang perforasi fossa interpeduncular, menurut wilayah suplai vaskular, dapat dipisahkan menjadi tiga kelompok yaitu arteri thalamic paramedian (PThAs) menyuplai ke paramedian thalami dengan variasi arteri Percheron yang mapan. Oklusi arteri Percheron menunjukkan pola khas klasik dari iskemia yaitu paramedian talamus bilateral disertai atau tidak dengan keterlibatan midbrain, termasuk bagian medial dari inti merah dan inti nervus kranial ketiga, arteri mesencephalic superior paramedian (SPMA) menyuplai rostral midbrain. SPMA dan PThA sering kali berasal dari trunkus tunggal, yang dikenal sebagai tipe Varian IIb dari arteri Percheron. Penyebab umum untuk infark di tegmentum midbrain kaudal dikenal sebagai arteri paramedian mesencephalic inferior (IPMA), arteri ini menyuplai tegmentum midbrain paramedian kaudal, termasuk commissure Wernekink, medial longitudinal fascicle (MLF), bagian anterior dari materi abu-abu periaqueductual, dan formasi retikuler (Liu et al., 2012; Zhou \& He, 2017).

Oklusi pada IPMA menyebabkan hasil CPMI. Sementara itu, CPMI bilateral dapat terjadi jika terdapat variasi di mana IPMA bilateral berasal dari common trunk. Selain itu, batang cabang fossa interpeduncular perforator dibagi lagi menjadi bagian ekstraserebral dan intracerebral. Sesuai dengan segmen cabang perforasi yang terkena dan variasi anatomi, MRI, dalam laporan sebelumnya, mengungkapkan morfologi CPMI yang beragam seperti lesi oval, bulat, lonjong, dan bentuk V. Untuk infark midbrain terdapat bentuk karakteristik dari bentuk "hati atau V" (Savoia et al., 2020).

Komisura Wernekink mengacu pada dekusasi konjungtivum brachium sebelum masuk ke nukleus merah tegmentum. Serat bilateral menyilang di daerah paramedian cauda midbrain bagian ventral ke aquaduktus untuk membentuk komisura Wernekink. Jika komisura Wernekink terdestruksi secara selektif, disfungsi serebelar bilateral dapat muncul (Zhou, He, Chao, Zhu, \& Wang, 2017).

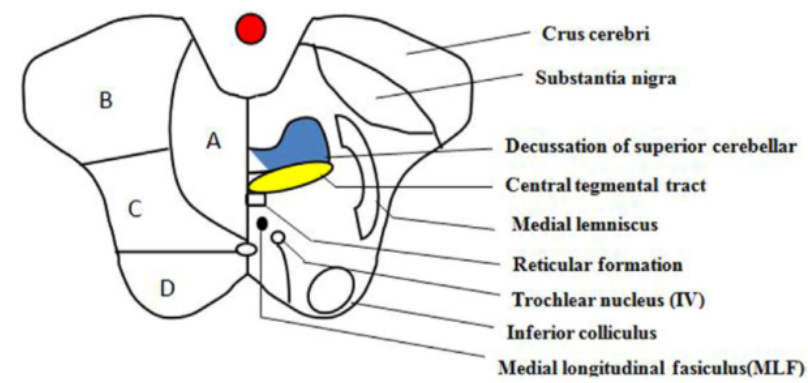

Gambar 1. Potongan melintang dari midbrain bawah setinggi colliculus inferior. Diagram skematis midbrain ini menggambarkan suplai arteri dan beberapa struktur penting di dalamnya. (A) Anteromedial, (B) anterolateral, (C) lateral, dan (D) dorsal (Savoia et al., 2020).

Kompleks Wernekink terdiri dari dua tractus materi putih penting yaitu tractus dentato-rubro-thalamic ascending dan tractus dentato-rubro-olivary yang menurun. Traktus dentato-rubrotalamic ascending menghubungkan nukleus dentata dari serebelum melalui batang serebelar superior ke nukleus merah kontralateral dan talamus. Traktus dentato-rubro-olivary yang turun menghubungkan dentate dan inti sela otak kecil dengan inti merah kontralateral melalui batang otak superior dan nukleus olivari inferior di medula. Lesi pada commissure Wernekink di cauda midbrain dapat merusak jalur dentato-rubrothalamic atau dentato-rubro- olivary, yang masing-masing menyebabkan tremor Holmes dini atau tertunda dan myoclonus palatal atau tremor onset tertunda (Mullaguri, Battineni, \& Chuquilin, 2018).

Studi menemukan banyak serabut saraf di midbrain, yang berhubungan dengan serebelum; oleh karena itu, ataksia adalah gejala dan tanda paling umum pada infark di midbrain. Degenerasi olivari inferior dianggap sebagai akibat dari kerusakan sirkuit segitiga Guillain-Mollaret, yaitu lesi pada tractus dentata-olivary dari nukleus dentata ke olivari inferior kontralateral melalui pedunkel serebelar superior dan traktus tegmental sentral setelah melintasi midline dekat inti merah. Oleh karena itu, lesi di midline, jika terletak di dekusasi pedunkel serebelar superior, dapat menyebabkan degenerasi olivari bilateral jika ada keterlibatan fiber saraf dentate-olivari bilateral saat mereka bersilangan. Namun, tremor palatal tidak terjadi pada setiap pasien dengan degenerasi olivary. HOD dapat terjadi kadang-kadang, tetapi tidak selalu, terkait dengan mioklonus palatal. Penghambatan struktur ini oleh jalur GABAergic yang terletak ventromedial ke konjungtivum brakium pada asalnya dari otak kecil. Gangguannya melemahkan neuron dari olive inferior dan dapat meningkatkan kopling elektrotonik yang menghasilkan pelepasan berirama dari kumpulan sel besar yang dapat menginduksi kontraksi ritmik dari soft palate dan struktur lainnya dan, akhirnya, dapat menyebabkan untuk degenerasi hipertrofik zaitun (Cosentino et al., 2016)

Lesi pada tegmentum midbrain paramedian dapat melibatkan fasciculus longitudinal medial yang mengakibatkan oftalmoplegia internuklear. Oftalmoplegia adalah tanda paling umum dari infark midbrain dalam beberapa laporan. Tanda okulomotor pada infark pada kauda 
paramedian bervariasi karena variasi bentuk lesi. Oleh karena itu, tidak mengherankan bahwa ini adalah tanda gangguan pergerakan mata yang paling umum. Oftalmoplegia internuklear adalah hasil dari gangguan jalur internuklear yang menghubungkan nukleus saraf abducens dengan pool motor kontralateral otot rektus medial di nukleus saraf okulomotor. Selain itu, kontingen serat yang terkandung dalam konjungtivum brakium dari neuron okulomotor di inti vestibular superior, yang menginervasi kolam motorik kontralateral dari rektus superior dan otot oblik inferior dapat menjelaskan paresis yang terjadi (Voogd \& Baarsen, 2014)

Gejala ptosis dan torsional nystagmus dapat dijelaskan dengan ekstensi rostral dari infark ke bagian inti okulomotorik/saraf dan inti interstitial Cajal (INC), masingmasing. Karena terdapat deviasi ke sisi kiri, lesi berbentuk "V" melibatkan INC kiri yang menyebabkan nistagmus torsi ipsilesional. Tanda ini jarang terjadi dan dapat terjadi akibat lesi midbrain kaudal yang hanya melibatkan INC tetapi membebaskan nukleus interstisial rostral dari MLF dan komisura posterior dengan nukleusnya. Defisit adduksi bilateral dapat dikaitkan dengan melibatkan MLF bilateral yang menghasilkan INO anterior bilateral (Mingming, Lishu, Weiyu, \& Li, 2019).

Dalam laporan, gait ataksia dapat dilihat pada 68\% dari 40 pasien, ataksia tungkai pada $50 \%$, dan oftalmoplegiahanya 35\% (Alhayek et al., 2020; Sheetal, Kumar, \& Thomas, 2020). Ataksia jelas disebabkan oleh gangguan dari dekusasi.

\section{Kriteria klinis-radiologis untuk diagnosis Sindroma Komisura Wernekink}

Pasien menunjukkan gambaran klinis dengan ataksia serebelar bilateral dengan gemetar berlebihan pada ekstremitas atas, baik saat istirahat maupun selama gerakan, sebagai ciri yang menonjol. Gejala-gejala ini kadang-kadang dikombinasikan dengan palatomyoclonus, suatu internuclear ophthalmoplegia, atau paresis dari rektus superior dan otototot oblik inferior (Sheetal et al., 2020).

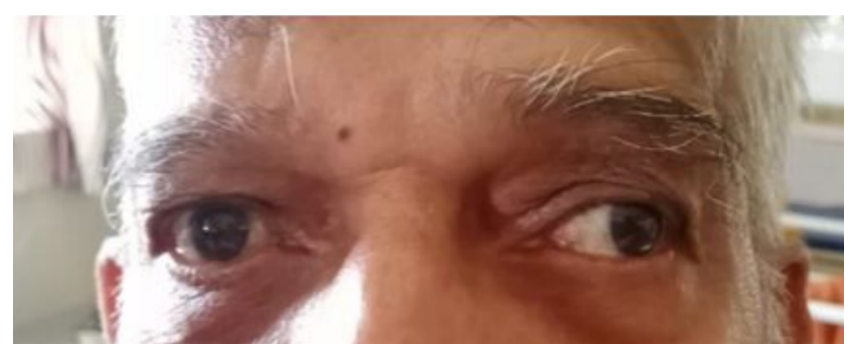

Gambar 2. Gangguan mata kanan, saat mencoba menatap ke arah kiri menunjukkan oftalmoplegia internuklear kanan.

\section{Kriteria esensial}

- Oftalmoplegiainternuklear ipsilateral

- Ataksia unilateral atau bilateral

- Bukti neuro-radiologis tentang keterlibatan caudal midbrain

Kriteria pendukung

- Tremor Rubral

- Mioklonus palatal

Pemeriksaan radiologis yang dilakukan dalam menegakkan diagnosis adalah MRI. Bergantung pada arteri yang terkena, MRI dapat mengungkapkan morfologi yang beragam, seperti lesi oval, bulat, lonjong, dan bentuk V. Lesi oval dan bulat, menyisakan midbrain ventral dianggap karena keterlibatan di paramedian arteri perforator. Infark akut pada komisura wernekink muncul sebagai hiperintensitas pada DWI di midbrain caudal paramedian, ventral ke akuaduktus. Lesi pada DWI atau FLAIR bisa berbentuk bulat, oval, berbentuk hati, atau berbentuk $\mathrm{V}$. Sebagian besar kasus unilateral tetapi beberapa infark melewati midline. Karena lesi mengganggu segitiga Guillain dan Mollaret, MRI tindak lanjut dapat menunjukkan degenerasi olivarium hipertrofik (Sheetal et al., 2020).

Tanda "heart-shaped" di medulla oblongata atau Pons dianggap muncul ketika infark terjadi di teritori anteriormedial dan anterior-lateral. Namun, untuk penampilan "heart-shaped" di infark kauda midbrain, yang mengakibatkan sindrom commissure Wernekink, harus melibatkan tiga kelompok cabang perforasi paramedian yang hanya memasok wilayah anteromedial di midbrain. Dengan memburuknya kondisi klinis, gambaran khas "heart-shaped" ditunjukkan pada pemindaian DWI (Zhou \& He, 2017).
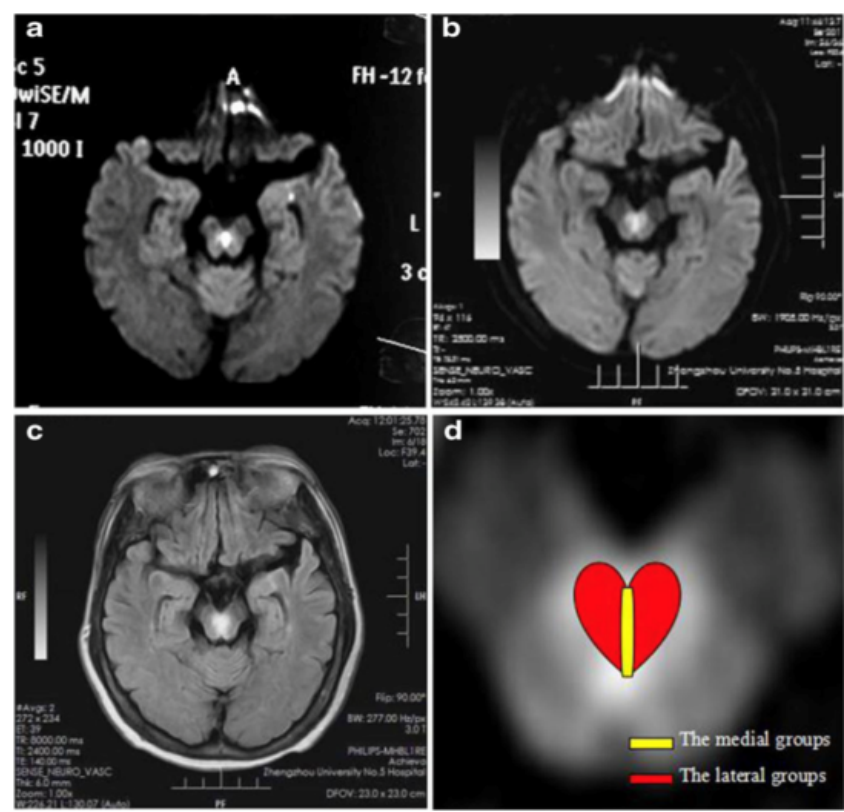

Gambar 3.A. Pemindaian otak pertama pada gambar MRI aksial berbobot difusi menunjukkan restriksi difusi di midbrain caudal paramedian sebagai bentuk kolom B vertikal. b, c Scan otak kedua pada citra MRI aksial menunjukkan hiperintensitas dengan karakteristik "heart shaped" pada citra pembobotan difusi dan citra Flair. d Gambaran "heart shaped" melibatkan kelompok medial dan lateral cabang perforasi paramedian di wilayah anteromeidal bilateral.

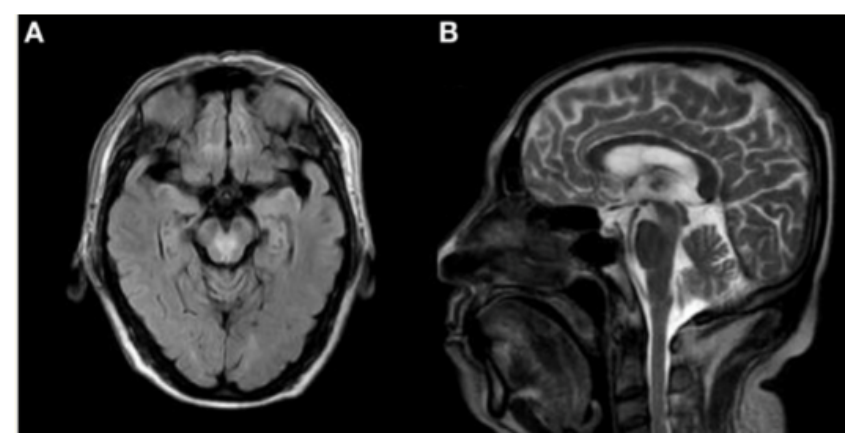

Gambar 4. Gambar axial fluid-attenuation inversion recovery (FLAIR) (A) dan gambar sagittal T2-weighted (B), menunjukkan area tampilan hiperintensitas "berbentuk hati" yang terletak di tegmentum midbrain kaudal. 


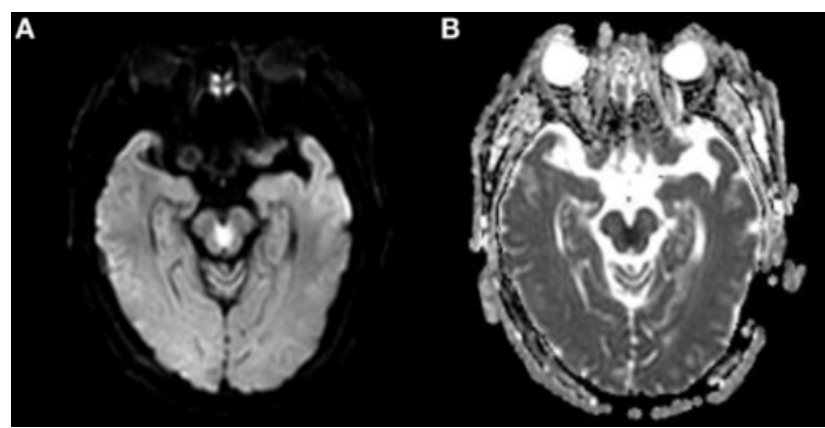

Gambar 5. A) Gambar diffusion-weighted image (DWI) pasien ditampilkan. Perhatikan lesi berbentuk "hati atau V" yang menunjukkan peningkatan intensitas di tegmentum midbrain kaudal. (B) Menggambarkan pparent diffusion coefficient map MRI (ADC). Lesi berbentuk "hati atau V" menunjukkan intensitas rendah pada $A D C$, konsisten dengan infark akut.

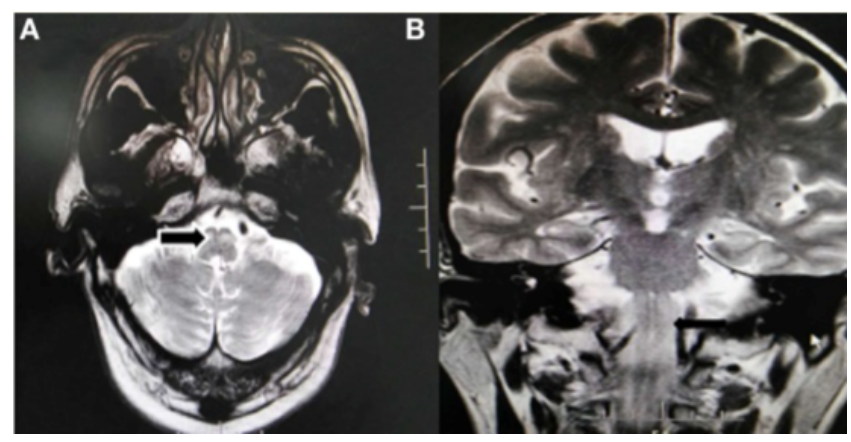

Gambar 6. MRI otak 1.5T, gambar aksial T2-weighted (A) dan gambar koronal T2-weighted (B) menunjukkan pembesaran simetris dan peningkatan intensitas dari kedua olivary inferior (panah).

\section{KESIMPULAN DAN REKOMENDASI}

Sindroma commissure Wernekink adalah sindroma midbrain yang langka. Kriteria klinis-radiologis untuk diagnosis Sindroma Commissure Wernekink terdiri dari oftalmoplegiainternuklear ipsilateral, ataksia unilateral atau bilateral dan Bukti neuro-radiologis tentang keterlibatan caudal midbrain dengan kriteria pendukung tremor rubral dan mioklonus palatal.

Pada temuan MRI, infark akut pada komisura wernekink muncul sebagai hiperintensitas pada DWI di midbrain caudal paramedian, ventral ke akuaduktus. Lesi pada DWI atau FLAIR bisa berbentuk bulat, oval, berbentuk hati, atau berbentuk $\mathrm{V}$.

\section{Acknowledgement}

We would like to express our gratitude to all those who have helped participate in this research, especially to the Health Polytechnic Ministry of Padang Padang, which have funded this research, through the DIPA fund of Health Polytechnic and the people of South Solok Regency who have carried out this research.

\section{Funding Statement}

The authors did not receive support from any organization for the submitted work and No funding was received to assist with the preparation of this manuscript

\section{Conflict of Interest statement}

The author declares that there is no potential conflict of interest in relation to the authorship and publication of this article.

\section{REFERENCES}

Alhayek, K., Aldabbour, B., I, H. A. R., \& Alanbar, M. (2020). Wernekink Commissure Syndrome : A Rare Cause of Bilateral Cerebellar Syndrome. Acta Neurologica Taiwanica, 29(3), 8689.

Cosentino, C., Velez, M., Nun, Y., Palomino, H., Quispe, D., Flores, M., \& Torres, L. (2016). Case Reports Bilateral Hypertrophic Olivary Degeneration and Holmes Tremor without Palatal Tremor : An Unusual Association. Tremor Other Hyperkinet Mov., 1-4. https://doi.org/10.7916/D87944SS

Liu, H., Qiao, L., \& He, Z. (2012). Wernekink commissure syndrome: a rare midbrain syndrome. Neurol Sci, 33(155), 1419-1421. https://doi.org/10.1007/s10072-012-0966-4

Mingming, D., Lishu, W., Weiyu, T., \& Li, T. (2019). Wernekink Commissure Syndrome secondary to A Rare "V"-Shaped Pure Midbrain Infarction: A Case Report and Review of the Literature. International Journal of Neuroscience, Q0), 1-22. https://doi.org/10.1080/00207454.2019.1707820

Mullaguri, N., Battineni, A., \& Chuquilin, M. (2018). Wernekink commissure syndrome with palatal myoclonus at onset: a case report and review of the literature. Journal of Medical Case Reports, 12(113), 1-7.

Savoia, S., Hashemiaghdam, A., Schindler, J., \& Salardini, A. (2020). Wernekinck commissure syndrome Sequela of a caudal paramedian midbrain infarction. American Academy of Neurology, o0(00), $1-3$. https://doi.org/10.1212/CPJ.0000000000000826

Sheetal, Kumar, A., \& Thomas, R. (2020). Wernekink commissure syndrome: clinico-radiological criteria. Nepal Journal of Neuroscience, 172), 1-7.

Voogd, J., \& Baarsen, K. Van. (2014). The Horseshoe-Shaped Commissure of Wernekinck or the Decussation of the Brachium Conjunctivum Methodological Changes in the 1840s. Cerebellum, (13), 113-120. https://doi.org/10.1007/s12311-013-0520-9

Zhou, C., \& He, Y. (2017). The B heart appearance ${ }^{\wedge}$ sign on MRI of Wernekink, s commissure syndrome caused by bilateral caudal paramedian midbrain infarction. Neuri Sci, 3-5.

Zhou, C., He, Y., Chao, Z., Zhu, Y., \& Wang, P. (2017). Wernekink Commissure syndrome secondary to Bilateral Caudal paramedian Midbrain Infarction presenting with a Unique “ Heart or V" appearance sign : Case Report and Review of the Literature. Frontiers in Neurology, 8(August), 1-5. https://doi.org/10.3389/fneur.2017.00376 